\title{
First trimester screening and progesterone levels in HIV positive women under HAART therapy
}

\author{
Ursache Alexandra lasi ${ }^{\infty}$, Tibeica Maria Alexandra, Onofriescu Mircea $\mathbb{}^{\circ}$, Luca Alexandru, \\ Matasariu Daniela Roxana ${ }^{0}$, Nemescu Dragos (1) \\ Women Clinical Hospital, lasi, Romania \\ Department of Obstetrics and Gynecology, "Grigore T Popa" University of Medicine and Pharmacy, lasi, Romania
}

\begin{abstract}
Objectives: HIV (Human Immunodeficiency Virus) that ultimately determines the development of AIDS evolved in time in a pandemic disease. Our study evaluated first trimester markers for aneuploidy, serum progesterone levels in first and second trimester in HIV positive pregnant women under HAART therapy.

Material and methods: It was a prospective study that took place between January 2017- December 2019 in "Cuza-Vodă" Hospital from Romania. We analysed first trimester PAPP-A, $\beta$ HCG, first and second trimester progesterone of 25 HIV positive pregnant women under HAART therapy and compared them with seronegative pregnant women.

Results: Both $\beta H C G$ and first and second trimester progesterone were lower in HIV positive women under HAART therapy.

These alterations of first trimester markers for aneuploidy might lead to an over estimation of the risk for Down syndrome.

Conclusions: Obstetricians need to know the alterations of first trimester markers for aneuploidy so they can correctly advise these women accordingly.
\end{abstract}

Key words: HIV; AIDS; pregnancy; antiretroviral therapy

Ginekologia Polska 2022; 93, 3: 224-228

\section{INTRODUCTION}

HIV (Human Immunodeficiency Virus) that ultimately determines the development of AIDS evolved disease in time in a pandemic. The virus targets the immune system, Thelper cells, specifically CD4 positive T cells, macrophages and dendritic cells. The socioeconomic impact is huge, and it represents a burden for the patient that needs to cope with the disease, the lifelong treatment and social stigma [1-3].

HIV has lately become a chronic condition with the introduction and development of antiviral therapy. In 2013 World Health Organization (WHO) recommended lifelong treatment regardless of CD4 count and viremia. This decision had a crucial impact on AIDS patient survivors [4-8].

While the benefits of antiretroviral treatment are undebatable, there are concerns, especially about fetal side effects. There are few studies that tried to evaluate side effects in uninfected exposed children from HIV positive mothers, with conflicting results. It is extremely important to try to assess fetal antiviral side effects and to try to improve these children's outcomes because the impact of HAART (highly active antiretroviral therapy) on vertical transmission and on the mother's mortality and morbidity makes it vital.

Previous literature data show that protease inhibitors have been associated with low progesterone production in trophoblastic cells and with the interference of CYP P450 (Cytochromes P45) enzymes. Low progesterone levels in pregnancy have been associated with fetal growth restriction (FGR), small for gestational age (SGA), premature birth, miscarriage, increased fetal morbidity and morbidity [9-13].

There is also scarce data about the influence of antiviral therapy on first trimester biochemical markers for aneuploidy. The influence of treatment on the values of PAPP-A (pregnancy-associated plasma protein A) and 3 HCG (Human chorionic gonadotropin) becomes very important in these patients because invasive fetal genetic testing raise the concern of increase vertical transmission.

\footnotetext{
Corresponding author:

Tibeica Maria Alexandra

Women Clinical Hospital, lasi, Romania

e-mail: alexandra.tibeica@yahoo.ro
} 


\section{Objectives}

We tried to observe the modifications of first trimester biochemical markers for aneuploidy and serum progesterone levels in the first and the second trimester of pregnancy in HIV positive women under HAART therapy.

\section{MATERIAL AND METHODS}

This was a prospective study that took place between January 2017 and December 2019 in "Cuza-Vodă" Hospital from lasi, Romania.

Inclusion criteria: HIV positive pregnant women under HAART therapy with complete obstetrical evaluations during pregnancy and with complete infectious disease evaluations during this time, with singleton pregnancy.

Exclusion criteria: multiple pregnancies, incomplete obstetrical or infectious disease evaluations, patients under progesterone treatment for premature birth, patients with high risk for premature birth.

All patients signed an informed consent approved by the ethical commission of Medicine and Pharmacy University "Gr. T. Popa", Iasi, Romania.

We analysed first trimester PAPP-A, $B$ HCG and progesterone of 25 HIV positive pregnant women under HAART therapy and second trimester progesterone of these patients. Ultrasound first trimester and second trimester evaluations were performed on Voluson E8 by two obstetricians trying to reduce the bias.

The values obtained in the first trimester, between 11-13 weeks of gestation from HIV positive pregnant women were compared with the values from 31 seronegative pregnant women without any medical or obstetrical conditions. Later in the second trimester, between 24-28 weeks of gestation, progesterone levels of HIV positive pregnant women were compared to those from 24 remaining seronegative pregnant women that presented themselves for evaluation.

\section{RESULTS}

Most of the 25 pregnant women were in C3 stage of disease $(24 \%-6$ cases) and came from rural areas. The age of these women was between 22-32 years, except for only one case that was 37 years old. Most of them were in the long-term survivor category, meaning that they were HIV infected in early childhood during their hospitalisation for diverse pathology ( $92 \%-23$ cases). There were only two new cases in this group, both of them being infected through sexual contact by their partners. Only one case (4\% of the cases) was at her third pregnancy, the rest, in equal percentage were at their first or second pregnancy (48\%). All of them were under HAART therapy containing a protease inhibitor. Most of them were on Kaletra and Combivir associated treatment. Kaletra contains Lopinavir, a protease inhibitor and Ritonavir as a booster, both inhibiting CYP3A4 isoenzyme. Combivir is a combination between Lamivudine and Zidovudine, two nucleoside/nucleotide reverse- transcriptase inhibitors (Fig. 1).

Seventy-two percent of the 25 patients in our study had undetectable viral load (18 cases), five cases had low viral load under 201 copies/mL. Only two of them had detectable viremia: one was 10.700 copies $/ \mathrm{mL}$ and one 6.060 copies/mL (Fig. 2).

All the data regarding serum dosing of aneuploidy markers and first and second trimester of pregnancy progesterone were analysed using One-way ANOVA test.

The group of HIV positive patients had a slightly reduced mean age than the seronegative patients ( 27 years \pm 3 years vs 28 years \pm 4 years; $p=0.570$ ), but a mean gestational age significantly higher ( 13 weeks and 1 day vs 12 weeks of gestation and 1 day; $p=0.002$ ) (Tab. 1).

Serum $\beta$ HCG values and the values of the MoM for $\beta$ HCG were significantly lower than the values of these parameters of normal pregnant women (24.25 vs $50.26 \mathrm{ng} / \mathrm{mL}$; $p=0.007$ and 0.77 vs $1.50 ; p=0.002$ ).

PAPP-A serum levels and the MoM for PAPP-A were lower in HIV positive pregnant women than the values from seronegative pregnant women, but the difference was not statistically significant ( 3.74 vs $3.89 ; p=0.876$ and 0.89 vs $1.22 ; p=0.151)$.

Progesterone levels were significantly lower between the two groups in both first and second trimester of pregnancy (21.79 vs 30.75; $p=0.001$ and 66.63 vs 136.36 ; $\mathrm{p}=0.001)$

The rate of FGR/SGA in our study was $20 \%$, three cases with FGR (under the third percentile for gestational age) and two cases with SGA (under the tenth percentile for gestational age). Twenty-four percent of the patients had

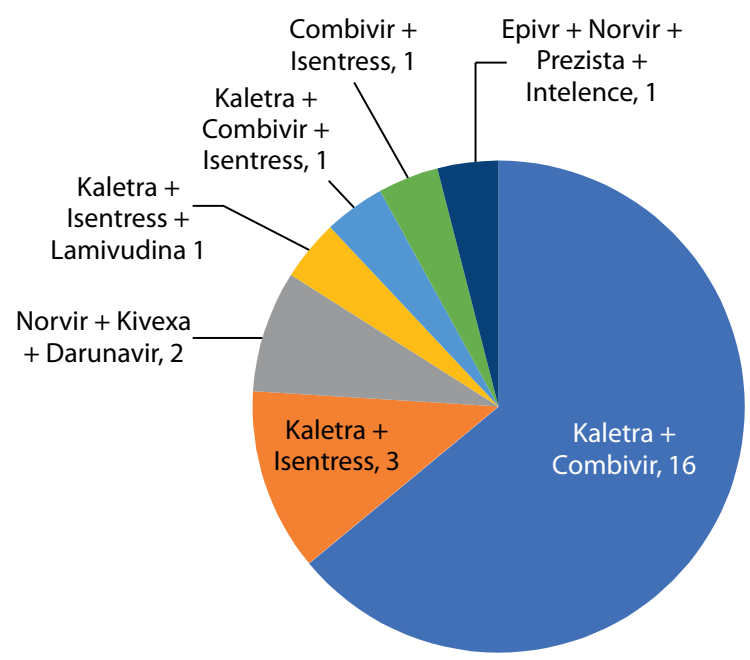

Figure 1. Associations of antivirals - HAART therapy — in our study 


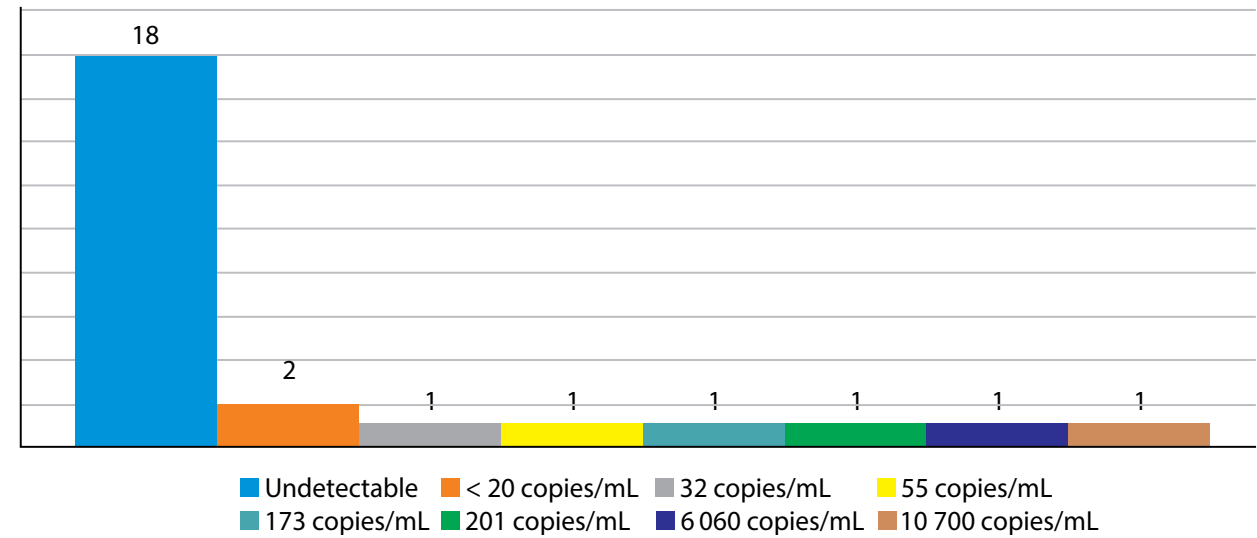

Figure 2. Number of cases depending on the viral load

Table 1. Evaluation of the serum first trimester aneuploidy markers and progesterone in the first and second trimester of pregnancy in HIV positive women under HAART therapy

\begin{tabular}{|c|c|c|c|}
\hline \multirow[b]{2}{*}{ Parameter } & \multicolumn{2}{|c|}{ Groups } & \multirow{2}{*}{$\begin{array}{c}\text { One-way ANOVA test } \\
-p\end{array}$} \\
\hline & $\begin{array}{l}\text { HIV positive } \\
\quad(n=25)\end{array}$ & $\begin{array}{l}\text { HIV negative } \\
(n=31 / 24)\end{array}$ & \\
\hline Age (years $\pm S D$ ) & 27 years \pm 3 years & 28 years \pm 4 years & 0.570 \\
\hline Gestational age (weeks \pm SD) & 13 weeks \pm 1 day & 12 weeks \pm 1 day & 0.002 \\
\hline$\beta H C G, n g / m L$ & $25.45 \pm 13.18$ & $50.26 \pm 42.20$ & 0.007 \\
\hline MoM $\beta$ HCG & $0.77 \pm 0.44$ & $1.50 \pm 1.02$ & 0.002 \\
\hline PAPP-A m UI/mL & $3.74 \pm 2.16$ & $3.89 \pm 4.45$ & 0.876 \\
\hline MoM PAPP-A & $0.89 \pm 0.36$ & $1.22 \pm 1.09$ & 0.151 \\
\hline $\begin{array}{l}\text { First trimester progesterone } \\
\mathrm{ng} / \mathrm{mL}\end{array}$ & $21.79 \pm 5.56$ & $30.75 \pm 9.10$ & 0.001 \\
\hline $\begin{array}{l}\text { Second trimester progesterone } \\
\mathrm{ng} / \mathrm{mL}\end{array}$ & $66.63 \pm 33.20$ & $136.36 \pm 26.38$ & 0.001 \\
\hline Viral load, $\mathrm{U} / \mathrm{mL} \pm \mathrm{SD}$ & $680 \pm 200$ & negative & \\
\hline
\end{tabular}

HIV — Human Immunodeficiency Virus; SD — standard deviation; PAPP-A — pregnancy-associated plasma protein A

premature birth, four at 36 weeks of gestation and only two between 34 and 36 weeks.

All patients gave birth by C-section and there were no children HIV infected after one year of life.

\section{DISCUSSION}

The huge positive impact of antiviral therapy in HIV positive patients is mildly shadowed by concerns about side effects, especially fetal side-effects. HIV positive pregnant women might be tempted to discontinue medication for the disease, due to worries about fetal health. There are few studies that tried to assess antiviral therapy side effects and to establish management directions to reduce their negative impact on exposed to antiviral HIV uninfected children. The prevalence of HIV exposed and antiviral exposed uninfected children raising due to the success of the therapy in prolonging lifespan and the reduction of the vertical transmission. So, it becomes very important to try to detect possible side effects and a real way to manage them in attempt to improve these children's quality of life.

Both serum first trimester markers for aneuploidy have lower values in HIV positive women under HAART therapy compared to HIV negative pregnant women with a more pronounced difference in $\beta$ HCG levels. PAPP-A is a marker of successful development of the placenta in the first trimester of pregnancy. Lower levels of this marker reflect a disturbance in the early development of the placenta.

Also, these alterations of the first trimester markers for aneuploidy in HIV positive pregnant women under HAART therapy might lead to an over estimation of the risk for Down syndrome. Fear of biased risk assessment might lead to unnecessary amniocentesis to exclude aneuploidy. Amniocentesis being an invasive procedure determines an increased risk for vertical transmission of the disease. In Poland, the cost of non-invasive fetal DNA testing form maternal blood is prohibitive and only a small number of patients can afford it $[14,15]$. 
Prematurity represents a significant socio-economic burden. Fifteen million children are annually being born under 37 weeks of gestation. The management of morbidity and mortality of premature infants are more difficult in underdeveloped countries where the incidence of prematurity is also higher. HIV infection and antiretroviral therapy increases the risk of prematurity, especially protease inhibitors. Studies have shown that protease inhibitors cause FGR (fetal growth restriction), SGA (small for gestational age) fetuses and premature birth due to progesterone depletion. Our study is in concordance with the results in literature that HIV positive pregnant women under HAART therapy, which includes a protease inhibitor, have lower progesterone levels. Protease inhibitors interfere with the activity of cytochrome P450 enzymes and this seems to be the mechanism responsible for lower progesterone levels in these women. All the studies focused on dosing progesterone in the second or in the third trimester of pregnancy and relate it to prematurity. Our study tried to evaluate if the progesterone levels are being decreased since the first trimester of pregnancy, from the critical moment in which the placenta forms. Confirming progesterone depletion since the first trimester of pregnancy, associated with lower levels of PAPP-A, we have a possible explanation for placenta anomalies in HIV positive pregnant women that leads later to the development of fetal growth impairment like FGR and SGA. We chose not to dose serum progesterone after 32 weeks of gestation because there was an increase in progesterone levels due to placental transfer of this hormone fetal precursors [9-12].

Both lower levels of progesterone and PAPP-A are associated with poor fetal outcome. Low levels of each of them are associated with increased risk for miscarriage, premature birth, SGA and FGR. Our results were similar to those of Chougrani et al who also observed a decrease in $\beta H C G$ serum marker for aneuploidy in HIV positive pregnant women under HAART therapy with the underestimation of the risk for Down syndrome. $[9,12,16]$.

None of our 25 patients had intermediary or high risk for aneuploidy. All the children were HIV negative after one year from birth.

\section{CONCLUSIONS}

Obstetricians need to know the alterations of the first trimester markers for aneuploidy that are present in this population so they can correctly advise these women accordingly. The ultrasound evaluation in these cases becomes more important because serum analysis can be a source of error and invasive testing stands under the risk of increased vertical transmission.
To reduce the risk for unfavourable fetal outcome we can try supplementation with exogen progesterone. The decrease in this pregnancy essential hormone is related to premature birth, FGR and SGA fetuses. By administering progesterone, we can try to overcome and improve these outcomes.

Because 18 of the HIV pregnant women from the 25 in our group had negative viremia, thus hypothetically the HIV virus effect is presumed to be absent, the alterations are due to antiretroviral treatment. And from the seven patients with detectable viremia, five had very low values, under 201 copies $/ \mathrm{mL}$.

Correct and complete information of these women about the risks and benefits of antiviral treatment, with management strategies to improve fetal outcomes might also assure a better compliance of the mothers to this treatment.

From our knowledge it is the first study done in our country that evaluates these aspects.

\section{Conflicts of Interest}

None

\section{REFERENCES}

1. Dorobăţ CM, Haliciu AM, Bejan C. Interdisciplinary correlations regarding the clinical and paraclinical evaluations in HIV-positive pregnant women. Rev Med Chir Soc Med Nat lasi. 2014; 118(3): 749-752, indexed in Pubmed: 25341296.

2. Sharp PM, Hahn BH. Origins of HIV and the AIDS pandemic. Cold Spring Harb Perspect Med. 2011; 1(1): a006841, doi: 10.1101/cshperspect. a006841, indexed in Pubmed: 22229120.

3. Smith $\mathrm{JH}$, Whiteside A. The history of AIDS exceptionalism. J Int AIDS Soc. 2010; 13: 47, doi: 10.1186/1758-2652-13-47, indexed in Pubmed: 21129197.

4. Wainberg MA, Jeang KT. 25 years of HIV-1 research — progress and perspectives. BMC Med. 2008; 6: 31, doi: 10.1186/1741-7015-6-31, indexed in Pubmed: 18976462

5. GreeneWC. A history of AIDS: looking back to see ahead. Eur J Immunol. 2007; 37(Suppl 1): S94-S102, doi: 10.1002/eji.200737441, indexed in Pubmed: 17972351.

6. Pau AK, George JM. Antiretroviral therapy: current drugs. Infect Dis Clin North Am. 2014; 28(3):371-402, doi: 10.1016/j.idc.2014.06.001, indexed in Pubmed: 25151562.

7. Fanales-Belasio E, Raimondo M, Suligoi B, et al. HIV virology and pathogenetic mechanisms of infection: a brief overview. Ann Ist Super Sanita. 2010; 46(1): 5-14, doi: 10.4415/ANN_10_01_02, indexed in Pubmed: 20348614.

8. Lu DY, Wu HY, Yarla NS, et al. HAART in HIV/AIDS treatments: future trends. Infect Disord Drug Targets. 2018; 18(1): 15-22, doi: 10.2174/187 1526517666170505122800 , indexed in Pubmed: 28474549.

9. Papp E, Mohammadi H, Loutfy MR, et al. HIV protease inhibitor use during pregnancy is associated with decreased progesterone levels, suggesting a potential mechanism contributing to fetal growth restriction. J Infect Dis. 2015; 211(1): 10-18, doi: 10.1093/infdis/jiu393, indexed in Pubmed: 25030058.

10. Price JT, Phiri WM, Freeman BL, et al. Vaginal progesterone to prevent preterm delivery among HIV-infected pregnant women in Zambia: a feasibility study. PLoS One. 2020; 15(1): e0224874, doi: 10.1371/journal. pone.0224874, indexed in Pubmed: 31995557.

11. Price JT, Vwalika B, Freeman BL, et al. Intramuscular 17-hydroxyprogesterone caproate to prevent preterm birth among HIV-infected women in Zambia: study protocol of the IPOP randomized trial. BMC Pregnancy Childbirth. 2019; 19(1): 81, doi: 10.1186/s12884-019-2224-8, indexed in Pubmed: 30813934. 
12. Papp $\mathrm{E}$, Balogun $\mathrm{K}$, Banko $\mathrm{N}$, et al. Low prolactin and high 20-a-hydroxysteroid dehydrogenase levels contribute to lower progesterone levels in hiv-infected pregnant women exposed to protease inhibitor-based combination antiretroviral therapy. J Infect Dis. 2016; 213(10): 1532-1540, doi: 10.1093/infdis/jiw004, indexed in Pubmed: 26740274.

13. Musyoki SK, Chelimo K, Mining SK, et al. The trends of progesterone hormone in advancing pregnancy of Human Immunodeficiency Virus-infected women: a cohort study in western Kenya. IJSTR. 2015; 3(7): 6698-6706
14. LaVigne KA, Seligman NS, Berghella V. Offering aneuploidy screening to HIV-positive women: routine counselling or not? BJOG. 2011; 118(7): 775778, doi: 10.1111/j.1471-0528.2011.02934.x, indexed in Pubmed: 21564478.

15. Patil M, PanchanadikarTM,Wagh G.Variation of papp-a level in the first trimester of pregnancy and its clinical outcome. J Obstet Gynaecol India. 2014; 64(2): 116-119, doi: 10.1007/s13224-013-0481-4, indexed in Pubmed: 24757339.

16. Chougrani I, Muller F, Marcelin L, et al. Combined first-trimester Down syndrome screening in HIV-infected women. Eur J Obstet Gynecol Reprod Biol. 2016; 203: 274-278, doi: 10.1016/j.ejogrb.2016.06.012, indexed in Pubmed: 27391901 